get the full benefit of all the departments if necessary. In this connection it is pointed out very truly that the necessity for a specialist to be in touch with all medicine and surgery is shown by the appointment of specialists in other departments on the staffs of special hospitals. It is possible, indeed it is extremely likely, that there will not be agreement in all quarters with Harman's point of view and that there will be many enthusiasts holding the opposite opinion. That there is much to be said for the general as against the special hospital is well illustrated by WatsonWilliams' two cases. Here the patients' safety depended upon the highest degree of skill on the part of a nasal surgeon. These two patients each suffered from sphenoidal sinus disease with which eye symptoms were associated. In the one case the left sphenoidal sinus was large and healthy and easily reached through either nasal passage, the right sinus small and highly infected. In the other case a large right sinus was infected while the small left one was healthy. The difficulty of diagnosis in such cases of irregularity of the sinuses is obvious, and it illustrates the advantage of having everything, so to speak, under one roof in rather an emphatic way. Do you think, Sir, that the readers of this journal might be invited to express their opinions in the correspondence column?

Yours truly,

ERnest Thomson.

Stirling.

\title{
OPHTHALMIC FOLK-LORE
}

To the Editor of The British Journal of Ophthalmology SIR,-In view of your annotation on ophthalmic folk-lore (Brit. Jl. of Ophthal., Vol. IX, pp. 638-9), the following extracts from a little-known book may interest your readers.

These extracts are translated from "Meddygon Myddfeu,"(a) the Welsh medical work said to have been composed in the 13th century by Rhiwallon, medical attendant to Rhys Gryg, lord of Llandovery and Dinefwr.

1. "A recent blow or a recent wound on the head. The sooner it is dressed the better lest blood should come on to the dura mater and coagulate there. From the time of raising the bone from the dura mater take violet and fresh butter and rub them together. If no violet is available take white of egg, and linseed, and rub them together, and place them to the wound, and then make an ointment of herbs and butter and tallow, and place them to it till it is healed. For that work of mercy the debt to the physician is a pound without food, or a hundred and eighty pence with food." 
2. "For pain in the eye. A cauterizing in the hollow under the eyebrow and another at the nape of the neck; and that is good for catarrh of the head."

3. "For red watering eyes. ${ }^{(b)}$ Place a seton under the two jaws and a cautery at the nape of the neck; and that is good for a running from the head."

4. "For severe dryness of the lids. (c) Take the juice of strawberries, the fat of a fowl, and May butter; press them together and place them in a horn, and when thou goest to sleep anoint thine eyes and thy lids well, and they will be healed."

5. "There are seven enemies to the eye : Weeping, watching, a growth, intoxication, adultery, a dry film, and smoke."

6. "For a film on the eye. Let the juice of ground-ivy be placed in it, and the film will break and the eye will be well and bright."

7. "The small boy who persistently cries. Anoint the two supraciliary ridges with the bone-marrow of a deer, and less frequent will be the weeping."

Among directions for maintaining health during each month of the year:

8. "Month of February. Bleed the thumb of the left hand. Obtain a salve and a draught, and that will keep the eyes well."

9. "For a film on the eye. Put in it the juice of ground-ivy."

A Latin fragment is attached to the text. In this is found:

"The juice of wormwood taken with honey and vinegar is useful to the sight, and makes the eyes clear."

\section{Yours truly,}

STOCKPORT.

G. ApThomas.

P.S.- (a) Diverres. Le plus ancien texte des Meddygon Myddfeu, published by le Dault, Paris, 1913. Diverres takes (b) to refer to dacryocystitis, and (c) to blépharite glandulo-ciliaire.

\section{OBITUARY NOTICE}

David Charles Lloyd Owen, M.D., F.R.C.S.I., for many years a member of the honorary staff of the Birmingham Eye Hospital and a leading ophthalmic surgeon in the Midlands, died suddenly on Christmas night after a short illness, at the age of 82 years. His death took place at his home at Bron-y-Graig, Harlech, where for some years he and Mrs. Lloyd Owen, who died in the autumn of 1924, had lived with their elder married daughter and her husband, Colonel George Lloyd.

Born in 1843, a son of the Rev. D. Owen originally of Darowen, Montgomery, Lloyd Owen received his medical education at the 